


\section{Affect, Mediation and Subjectivity-as- Encounter: Finding the Feeling of the Foundling}

\section{Abstract}

1.

2.

3.

4.

5.

6.

7.

8.

9.

10.

11.

12.

13.

14.

15.

16.

17.

18.

19.

20.

21.
This article will take the subject of affect as a space of critical reflection on the limits of museums when conceived primarily as communications media. Drawing from a range of interdisciplinary debates across media and cultural theory, including the field of affect studies and approaches to subjectivity, embodiment and mediation, the article will outline some core issues of relevance to curatorial practices. I will pose the question of what it might mean to enter into suggestive relations with anotherhuman and non-human - by focusing upon the embodied experience of visiting the Foundling Museum in London. The article will attempt to 'find the feeling of the foundling' in order to raise critical and creative questions about the entry of affect into the arts and humanities, and ways of newly conceiving interactive publics no longer considered primarily as consumers of meaning.

The entry of affect studies into the arts and humanities has been driven by an awareness that social and natural phenomena are complex, processual, indeterminate, relational and constantly open to effects from contiguous processes. At the same time, the awareness and experience of these processes is increasingly aligned to non-conscious, non-cognitive dimensions of experience: sensations, intensities, atmospheres, memories, perceptions and forms of attention that captivate subjects and exceed conscious, rational attention. Theories of affect also invite a reconsideration of the role of the body and embodied forms of sense-making in being and becoming.

\section{Keywords}

affect and museums affective embodiment mediation in exhibitions subjectivity-asencounter feeling and audiences transliminality mediated perception Foundling Museum, London 
It is no surprise therefore that the purview of the curatorial should also be interested in the potential offered by the field of affect studies. Encounters in museums and galleries between publics and objects, and artefacts and practices, invite questions as to how these interactions might be modulated, amplified, mediated and choreographed. This article will respond to the challenges of curating affect by transposing issues from media and cultural theory into the space of the gallery or museum. I write as an interdisciplinary scholar situated at the intersection of critical psychology, affect studies and media and cultural theory. I am not a curator but I have been interested throughout my academic career in subjectivity and embodiment and how practices, techniques, objects, artefacts and technologies shape, augment, extend and orchestrate those experiences that open the subject to the other, human and non-human.

This special issue invites contributors to explore how a focus on affect foregrounds registers of experience that have potentially been neglected by approaching museum or gallery audiences primarily as consumers of meaning. As with other disciplines, the focus on the communicative activity of choreographed spaces (such as galleries, exhibitions or museums) when understood primarily as transmitters of symbolic meaning and interaction, does not exhaust the design possibilities opened up by foregrounding affect. The disciplines of media and cultural theory have a different intellectual genealogy and formation to art, design and related disciplines. However, the way in which affectivity has entered into and reshaped discussions of mediation within these fields of study might be instructive for thinking through how affective processes might be enacted, performed, extended and modulated within the context of practices of curation.

My own particular approach to issues of the curation, performance, design and actualization of what might be termed affectivity or affective processes also derives from my interest in creative and critical forms of experimental life that are often excluded from mainstream science. I have explored these forms of life specifically within the context of 'threshold phenomena' - that is, phenomena that blur the boundaries between inside and outside, self and other, material and immaterial, past and present, and the human and the technical (see Blackman 2012). This includes hypnosis, suggestion and varied forms of contagion or networked virality, which appear to spread across populations with a speed and rapidity that defies the action of rational logic (Sampson 2012). Under this designation I also include voice hearing and psychic phenomena, such as telepathy, mediumship, precognition (the ability to feel the future) and automatic writing. These phenomena are usually or often approached as abnormal perceptions, sometimes as forms of psychopathology, or as puzzling anomalies that remain on the margins of science. They are also experiences that artists and curators have had a longstanding fascination with, and importantly I will argue, open up neglected issues when they are foregrounded as important and interesting modalities of communication.

Under the designation of threshold phenomena, I also include occurrences that are associated with more embodied or somatic forms of knowing. This includes forms of knowledge that are often described as tacit, or that are related to the ability to attune to others. These others

1. 2. 3. 4. 5. 6. 
1.

2.

3.

4.

5.

6.

7.

8.

9.

10.

11.

12.

13.

14.

15.

16.

17.

18.

19.

20.

21.

22.

23.

24.

25.

26.

27.

28.

29.

30.

31.

32.

33.

34.

35.

36.

37.

38.

39.

40.

41.

42.

43.

44.

45.

46.

47.

48.

49.

50.

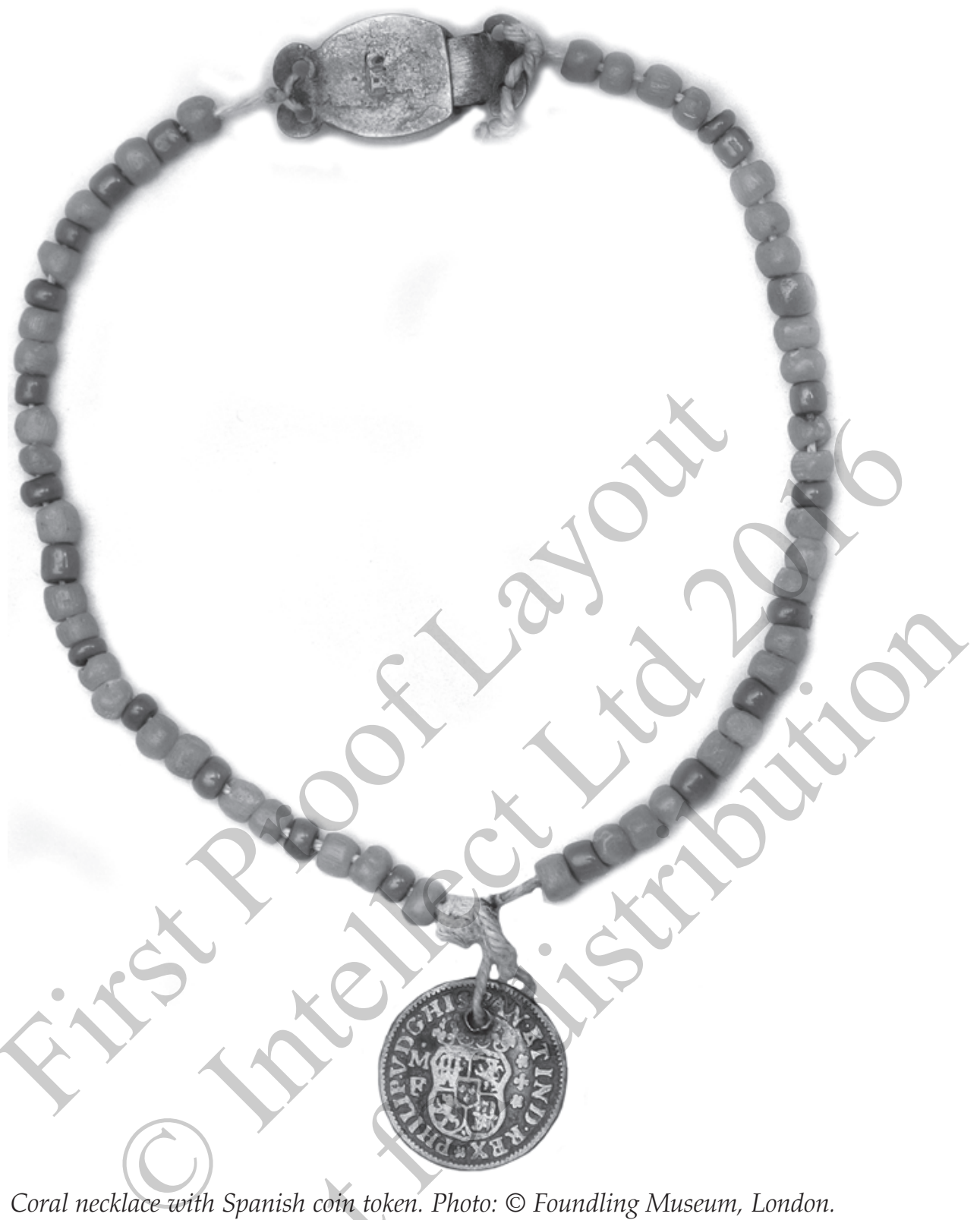

Coral necklace with Spanish coin token. Photo: () Foundling Museum, London.

might be both human and non-human. Threshold phenomena as I am considering it also comprise rhythmic forms of communication, inspiration and kinaesthetic forms of intelligence or intelligent learning. I have a particular fascination for curious hybrid phenomena, which often confound expectation, confuse certainty and for many scientists represent puzzling anomalies that continually defy or haunt desires to know. I bring this archive of minor experiences together under the rubric of weird or even qweird science (Blackman 2015b). It is this science and its potential for opening up affectivity that I will explore by developing the concept of transliminality. 
1. For a further discussion of the relationship between affectivity and hauntology, see Blackman (2015b).
Transliminality provides a link to a foundational book in museum studies by Carol Duncan (2005), which discusses exhibitions and museums as 'liminal spaces', offering a 'time out of normal time', marked by thresholds of entry and exit, for example. Rather than explore exhibitions and museums as 'time out of normal time' (leisure time, perhaps), I will explore museums and exhibitions as also shaped by transmedial time. The concept of transmedial time is inspired by the writings of Rey Chow, a postcolonial theorist, who asks what happens 'When time loses its potential to become fugitive or fossilized - in brief, to become anachronistic?' (2012: 5). Chow asks this question in relation to social and digital media, which she argues have the potential to set in motion different times and temporalities. Transmedial time is time performed hauntologically, characterized by 'non-linear temporalities' (Carsten2007: 2; Cho 2008; Gordon 2008). Chow describes transmediality in the context of digital and social media through the concept of entanglement (influenced by Karan Barad's writings), which is extended by figurations such as knots, masks, traps, mazes or shadows. She develops performative methods of capturing and staging such 'topological looping', including montage, collage and tableau (2012: 1, 5).

Chow's concept of 'scenes of entanglement' has been particularly important in my own thinking, where different temporalities and multiplicity of times might intrude, criss-cross, over-lap, move and have the potential to be re-moved within specific assemblages of meaning, affect and matter (Rheinberger 1994). I will develop these concepts in the context of my work on affect and consider the usefulness of approaching curation as a performative practice that has the potential to perform, move, animate and re-move those narratives and experiences that are often disqualified, disavowed, submerged, displaced and discredited within particular scenes of entanglement. In other words, I will approach curation as a practice that has the potential to work affectively and hauntologically.

Hauntology is a broad interdisciplinary field of study and practice that extends across the arts and humanities, has a particular place in philosophy and has entered into discussions of media, such as film, photography and television. Hauntology has a particular place in the lives of oppressed and marginalized peoples and those suffering from traumatic memories that blur the historical and the personal and the past and present. Avery Gordon suggests that hauntological analysis is a way of focusing on how people sense, intuit and experience the complexities of modern power. It focuses on 'what is usually invisible or neglected or thought by most to be dead or gone' (2008: 194). ${ }^{1}$

In the article, I will develop the concept of mediated perception in order to stage what might be at stake. The concept of mediated perception refers to those forms of distributed perception (the conjoining of the human and non-human) that have the potential to shape, design, amplify, extend, attend to and enact registers of experience that exceed cognition and conscious awareness and might allow one to 'see' what usually remains hidden. Although some of the phenomena and experiences I discuss might feel tangential to curatorial practice, I hope to show that threshold phenomena have much to impart to understanding of the contexts of the curatorial.
1.

3.

4. 
1.

2.

3.

4.

5.

6.

7.

8.

9.

10.

11.

12.

13.

14.

15.

16.

17.

18.

19.

20.

21.

22.

23.

24.

25.

26.

27.

28.

29.

30.

31.

32.

33.

34.

35.

36.

37.

38.

39.

40.

41.

42.

43.

44.

45.

46.

47.

48.

49.

50.

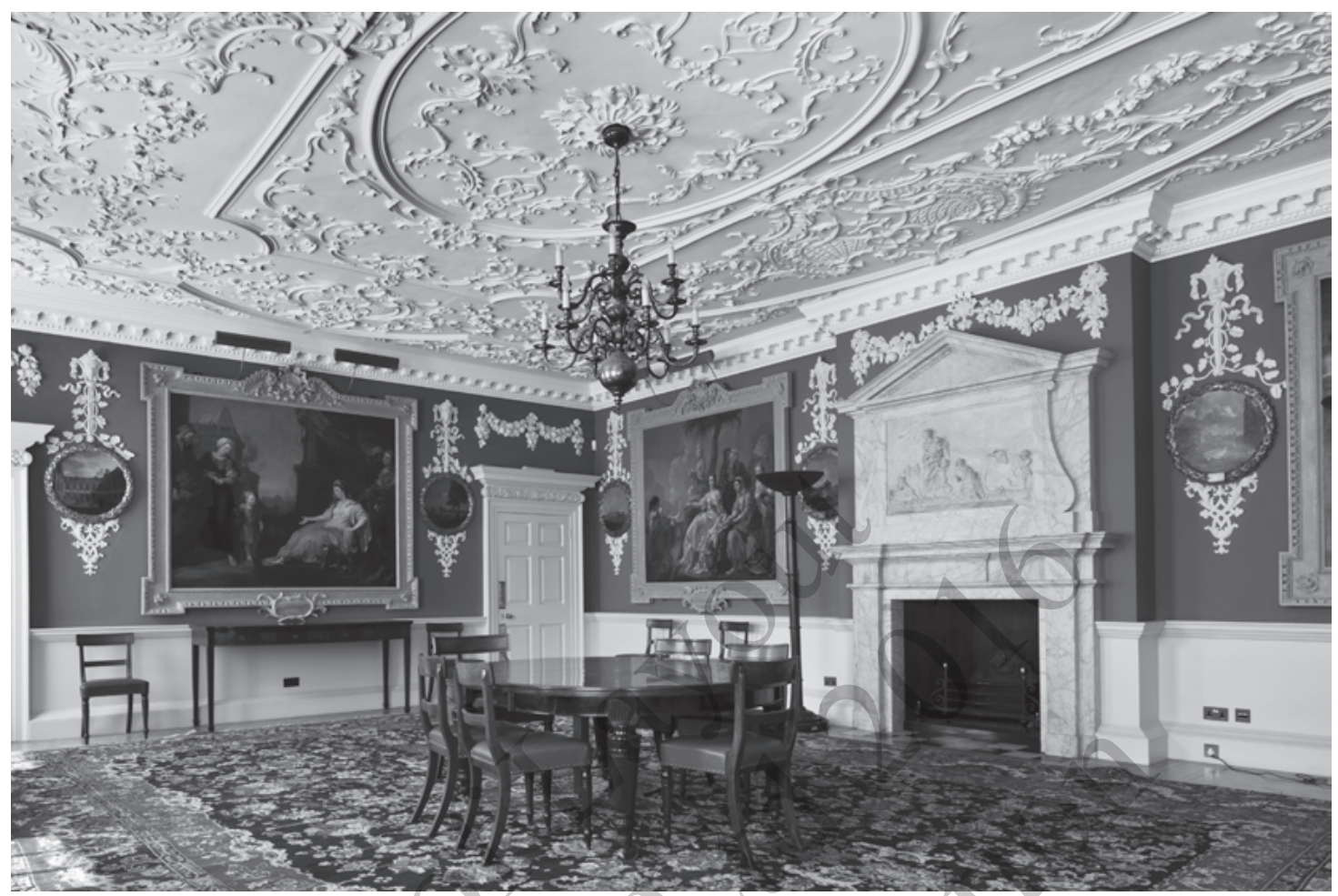

The Court Room. Photo: () Foundling Museum, London.

The article stems from my own experience of resonance with an exhibition at the Foundling Museum in London, which documents the experiences of abandoned and orphaned children and houses the Foundling Hospital Art Collection. The exhibition, Sir Jacob Epstein: Babies and Bloomsbury (2015), and the existing art collections came to my attention via a $B B C$ Radio London broadcast featuring one of the curators on the Robert Elms talk show. This feature moved me profoundly and the experience of being overcome by tears has provided a central affective focus for discussing some of the conceptual issues at stake. The article will reflect upon the intensity of feeling and my subsequent visit to the museum and exhibition.

\section{Mediation, Audiences and Affectivity}

With the advent of social and digital technologies, many media theorists subscribe to the view that the 'people formally known as the audience' need to be reimagined as prosumers (rather than consumers of symbolic meaning). This distinction is seen to rescue audiences from an assumed passivity, which is connected to the one-to-many logic seen to describe broadcast models of communication. In the context of digital media, audiences are now approached as potential co-producers of meaning and content. Part of this argument relates to the affordances of digital technologies, which allow more decentralized, distributed and interactive modes of engagement. Where audiences or publics are considered 
as collaborators, how to enlist such capacities through the use of digital technologies and related activities is a key concern. The idea of media as texts to be decoded for meaning is now long past its sell-by date and a set of new vocabularies are forming around this problematic.

One response to some of these assumptions and the reimagining of the audience as users, whose desires for more interactivity are afforded by social and digital media, comes from the new media theorists, David Bolter and Richard Grusin (2000). They attempt to displace the binary between old and new audiences, which are mapped onto distinctions made between old and new media, and rather explore all communication media as 'hybrid objects'. They borrow this term from the work of the French sociologist Bruno Latour, the key proponent and architect of Actor Network Theory (ANT). Latour (2005) rejected the idea that one can isolate distinct domains or entities, such as the social, economic, technical, aesthetic, psychological or cultural. Rather than approach objects as composed, pre-formed entities, he explores how entangled relations are always in-composition, thus moving attention to the processes through which objects, subjects, entities and experiences stabilize within particular assemblages. One key question is whether these moves, which displace the psychological subject as the subject of experience, open curation up to new possibilities and imaginaries: what might it mean to approach curatorial practice as amplifying, mediating, extending and enacting those entangled relationships that constitute art or museum objects as hybrid media? How might audiences be choreographed and orchestrated to experience the perception and registering of entangled relational processes? And what technologies of mediation might one need to invent in order to bring the exhibition alive?

\section{Experimentation, Bodies, Interfaces}

The concept of mediation within media studies has a long history, which television changes the experience of ceremonial events. One assumption challenged by Kurt Lang and Gladys Lang (1961) was that audiences might assume that experience is more immediate when it is not mediated by technical forms - that is, when audiences experience a live event. This assumption rests on the idea of direct or authentic experience (of an artwork, museum collection, televisual event, etc.). Although the primacy of live experience is still part of popular discourse and creative practice, in fact media theorists have found that audiences often feel more connected to an event when it is mediated, but that successful mediation requires the simultaneous erasure of the signs of mediation. This is termed the double logic of remediation (Bolter and Grusin 2000) and is a paradox that invites further reflection.

How might a curator design an exhibition such that its public(s) feel a sense of connection but do not overly recognize the choreography and mediation of the experience? This paradox of actuality is a curious phenomenon, and one that has a long history within studies of television, cinema, radio and other communications media (see Kavka 2008). It relates to the processes through which mediated forms of intimacy and connection are 


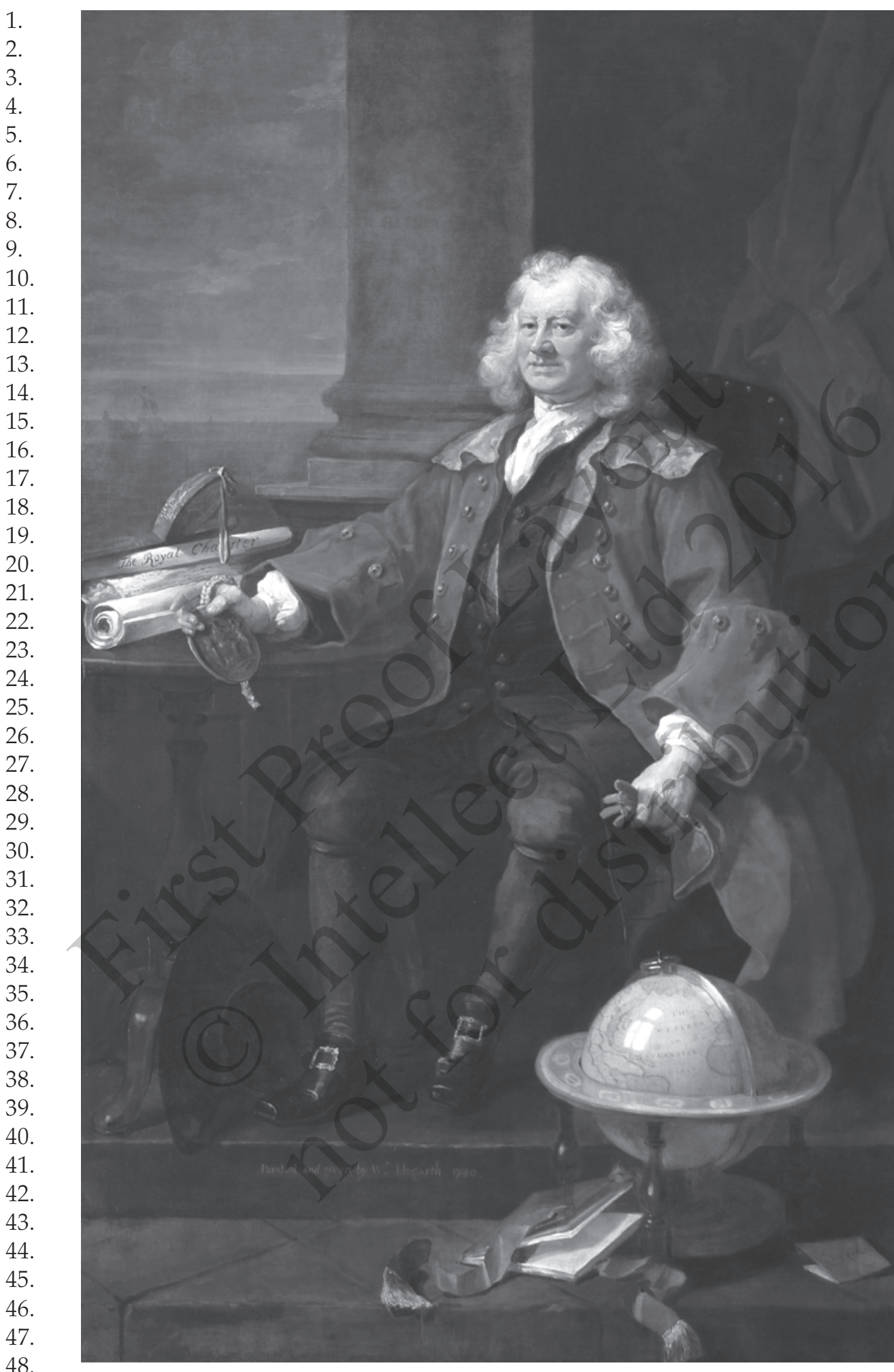

49. William Hogarth, Captain Thomas Coram (1740), founder of the Foundling Hospital. 50. Photo: () Foundling Museum, London. 
achieved by the use of particular devices and techniques of mediation, which often and usually recede from awareness. These mediated forms of intimacy are experienced through a sense of immediacy - as experiencing an unmediated reality, which feels direct and non-cognitive. This is what David Bolter and Richard Grusin (2000) also term 'presentness'.

Presentness, of course, is a vague and ambivalent concept. What do audiences feel when they feel immediacy? Why does this create a sense of vitality and connection, of being there and experiencing something directly as if it is unmediated? Is this part of what might be at stake in curating affect, or are there issues that exceed this assumption? Very few media theorists would subscribe to the idea that experience can ever be unmediated, and many media theorists working across affect and mediation within cultural theory, would argue rather that 'life is mediation' (Kember and Zylinska 2012). That is, there is no originary humanness that is separate from technicity; individuals come into being through relations that are simultaneously technical, political, economic, cultural, symbolic, aesthetic and psychological (see Blackman 2008, 2012). The experience of presentness also draws attention to the more affective dimensions of mediation and opens up some of the challenges of attuning to audience's desires for such an experience. The trend for presentness can also be found within architectural theory, and is captured by the idea of immersive architecture - of buildings that are not experienced as monuments, but rather as affective experiences. Indeed, Beatriz Colomina (1992) has argued that architecture only becomes modern when it engages with media understood in this way - as technologies of mediation rather than as medium-specific technical forms or spatialized entities such as television, radio, camera and so on. This shift in architectural theory speaks to Reyner Banham's (1986) observation that the majority of iconic buildings of the twentieth century are known through photographs, rather than embodied experiences.

Of course, immediacy is not the only desire that audiences might bring to galleries and exhibitions. As Bolter and Grusin (2000) also argue, there is a competing logic that is enacted by technologies of mediation, which they refer to as hypermediation. Bolter and Grusin's project is to produce a 'genealogy of affiliations' between old and new media, and to that extent they are interested in tracing the genealogy of a competing or sometimes coexisting media logic, which conversely draws attention to processes of mediation or construction (where remediation rather erases the signs of mediation, for example). This logic of hypermediation, they argue, has an affiliation with modernist and postmodern art and is characterized by montage, collage, fragmentation, indeterminacy and heterogeneity. They find this visual aesthetic within graphic and pop art of the 1960s and 1970s, and argue that it is repurposed, reworked and reimagined within the hypertext of the Internet and the visual logic of social media such as Facebook, for example. It opens up to multiplicities of experiences and produces a field, which competes for attention and might be equated to the full range of the human sensorium.

It is certainly one that has been aligned and marketed as enacting more interactivity for audiences who are recast as users. It is the subject's task to sort and organize what competes for attention, while how attention

1. 2. 3. 4. 
1. is always already orchestrated, organized and enacted simultaneously

2. disappears from view (the algorithm as an automated enactment of medi-

3. ated perception). The erasure or disappearance of mediation within this

4. context is at odds with the aims of much contemporary art practice (which

5. was about disrupting convention and socialized modes of perception), but

6. similarly retains an emphasis on media-as-process rather than media as

7.

8.

9.

10.

11.

12.

13.

14.

15.

16.

17.

18.

19.

20.

21.

22.

23.

24.

25.

26.

27.

28.

29.

30.

31.

32.

33.

34.

35.

36.

37.

38.

39.

40.

41.

42.

43.

44.

45.

46.

47.

48.

49. Enamel token from Ann Higs (above) and wooden pot with rouge token (below). Photos: (c) Foundling

50. Museum, London. 
static entities. One of the less developed aspects of Bolter and Grusin's work relates to the problematic of subjectivity - of how 'we' participate within processes of mediation. This is a crucial yet vexed question and one that is important for reimagining audiences as co-producers of presence, immediacy and affectivity.

The work on mediation, which derives from the challenges of studying the difference 'new media' make to peoples' lives, draws attention to the different media logics, which compete, coexist and have complex genealogies of existence. It suggests that mediation recast within practices of curation, for example, might approach the gallery or exhibition as an interface that attempts to attune to, orchestrate, rework and reimagine those entangled relations that objects, entities, artworks and practices might articulate. What might it mean for an exhibition to be brought to life such that audiences feel a connection? And are there other forms of connection or actuality that exceed the logic of remediation or hypermediation? In order to establish what might be at stake in these distinctions (remediation and hypermediation, for example), I will situate this discussion within an analysis of embodied forms of sense-making, which extend beyond the consumption of symbolic meaning. What I want to share with readers in this context is what I have learned from considering issues of bodily affectivities, models of selfhood/embodiment, and processes and practices of mediation in the context of threshold phenomena, including the phenomenon of suggestion.

\section{Orchestrating Suggestion}

How does a curator conceive of embodied forms of sense-making as part of curatorial practice? What do threshold phenomena - that is, experiences that blur the boundaries between the self and other, inside and outside, natural and historical and material and immaterial - open up in relation to the curation, amplification, orchestration and modulation of affective experience? In order to consider these questions, I will focus upon an example of a 'threshold phenomenon' that forms one of the central modes of reflection and analysis in my recent book, Immaterial Bodies: Affect, Embodiment, Mediation (2012). That threshold phenomenon is suggestion, and the question of what it might mean to enter into suggestive relations with another, human and non-human, is a question that crosses the arts, humanities, sciences and medicine. By suggestive relations, I mean the capacity to be moved by artefacts, objects, entities, devices, images, techniques and so forth.

How suggestive relations can be modulated, amplified, choreographed and curated has a long auspicious history (see Blackman 2012; Borch 2012). This includes viewing suggestion as an ordinary modality of sociality in the work of the nineteenth-century psychologist and sociologist Gabriel Tarde, through to its appearance within modern psychology as a capacity primarily aligned to the so-called primitive and irrational (see Blackman 2007). The capacity for suggestion became considered an abnormal or marginal perception aligned to so-called deficits of cognition and habit. It was associated with certain groups and people who have been erroneously considered more susceptible and vulnerable to 
1. persuasion, contagion, and the actions and machinations of others (see

2. Blackman and Walkerdine 2001). This discourse of the vulnerable mind

3. (or 'mob' or group mind) does symbolic and actual harm in preventing

4. the consideration of the seductive workings of power, and assumes that

5. normative subjectivities and psychological health and well-being are

6. based upon a clearly bounded rational subject exercising control and

7. mastery over its environment (see Orr 2006). It is based upon rationalistic

8. assumptions of ideal communication that relies upon the negotiation of

9. the meaning understood primarily as information.

10. Such an approach to communication-media reifies cognition and posi11. tions the museum or gallery audience as code-breakers deciphering what 12. has been encoded by the juxtaposition of particular texts, objects, artefacts 13. and design interfaces. Disembodied and operating primarily from the neck 14. up, it is perhaps an anti-affective approach to the design and curation 15. of exhibitions in museums and galleries, and is one that I suspect most 16. curators would question and problematize in relation to their own curato17. rial practices. This discourse is also one that enacts a particular colonial 18. history that has helped to shape specific socialized modes of attention and 19. perception through technologies of distancing, othering, projection and 20. the animation of particular normative fantasies and desires (see Bennett 21. 1995). It contributes to an assumed subject-object distinction that places 22. the museum or exhibition as 'time out from the ordinary'.

23.

24.

25.

\section{Finding the Feeling of the Foundling}

Curation and affectivity come together in the context of a particular museum exhibition and my own experiences of profound resonation. I felt moved to tears listening to a radio broadcast where Gill Hedley, a guest curator from the Foundling Museum, spoke to Robert Elms, a BBC Radio London talk show host, about the exhibition Sir Jacob Epstein: Babies and Bloomsbury. She spoke about the museum, which is part art gallery, part museum, part educational establishment, part archive, part outreach, part historical monument and part research resource for interested publics. In that sense, one can see that the museum is a good example of a hybridobject, where curatorial practice mustattune and be sensitive to the entangled relations at play. It was my own feeling of being moved to tears upon hearing about the history of the museum and its current art exhibition that sent me on a journey to reconstruct its curatorial effectivity and affectivity. Here, I understand curatorial practice in its capacity to enact and amplify potential 'scenes of entanglement' in order to educate, inform and move audiences within more intensive realms and registers of experience.

The Foundling Museum can be found on Bloomsbury Square in central London. It hosts artefacts, art collections and resources associated with its history as a public hospital for foundlings - children who had either been abandoned or given up by their caregivers due to poverty, death, destitution, disease or illegitimacy. To that extent the museum's history also articulates the public regulation of female sexuality and the place where the shame, secrecy and silence surrounding so-called deviant female sexuality were housed, contained and re-presented as an act of philanthropy. The forms of speech that articulated the grief, loss and trauma 
surrounding those children and families whose lives became part of the Foundling Museum's history are now told through the material traces of lives once lived in the institution. These presences remain as coins, jewellery, swatches of material from items of clothing, pieces of metal, wood and other materials, as well as more recognizable objects, such as hatpins or bracelets.

The communicative function of these objects assumes the burden of representing an idiosyncratic life. One of the conditions of entry to the hospital was that the child's identity was severed from that of the family and replaced with a token, which might allow identification of the child's genealogy at a later point. These tokens are contained in glass cabinets in regimented rows, which in their anonymity allow for reflection on who the individual children might have been, what their family and personal histories were, and how the matter might be reanimated to speak to museum audiences in the present. These tokens remain as absent-presences as no stories can be told; they exist as epistemic foreclosures.

The central theme of the curatorial project takes on the challenge of how to reanimate these lives and revitalize the inert matter. The ground floor of the museum is devoted to the children whose lives became entangled with the hospital, and who now remain only as numbers and tokens found in glass and wooden cabinets. The sense of the lost or haunted objects is remediated in the exhibition by a subsequent cabinet that provides some detail of those foundlings who lived and grew up in the hospital, until its closure in 1954, and whose stories can be told and brought to life through their own words and reflections. These oral histories are also continued online (Foundling Museum n.d.). This hauntological feeling is further underscored later in the exhibition by art exhibits made and funded through different projects, in order to convey the feeling of anonymity, loss, grief and trauma that surrounded these lives. In the context of austerity in Britain and the widening gap between the rich and poor happening across the globe, this particular scene of hauntological entanglement intrudes onto the exhibition. It is here and not-here, left at the door but remaining as a powerful absent-presence.

During my visit, groups of children tour the museum. The children scream, laugh, are distracted and are invited by various adults to consider the informational aspect of the curation; they are here to learn and to engage in play, which is primarily considered educational. Despite or perhaps in spite of the liveliness of these children, I feel moved to what is absent - to those stories that haunt the objects and that impel me to weep. I wipe the tears from my eyes and ascend the stairs to the first floor, which houses the stories and artefacts of the beneficiaries who made the hospital possible.

The stories of these upper-middle-class white male philanthropists, of course, can be told. Their stories are documented. They include that of the composer George Frederic Handel (1685-1759), and displays of paintings originally part of the hospital's art collection commissioned or donated by specific artists to fund the life of the institution. The success of the hospital in part was due to its function as a public space and gallery (including a classical concert programme), which brought the hospital into the community, as well as encouraging philanthropists to support its mission.

1. 
1.

2.

3.

4.

5.

6.

7.

8.

9.

10.

11.

12.

13.

14.

15.

16.

17.

18.

19.

20.

21.

22.

23.

24.

25.

26.

27.

28.

29.

30.

31.

32.

33.

34.

35.

36.

37.

38.

39.

40.

41.

42.

43.

44.

45.

46.

47.

48.

49.

50.

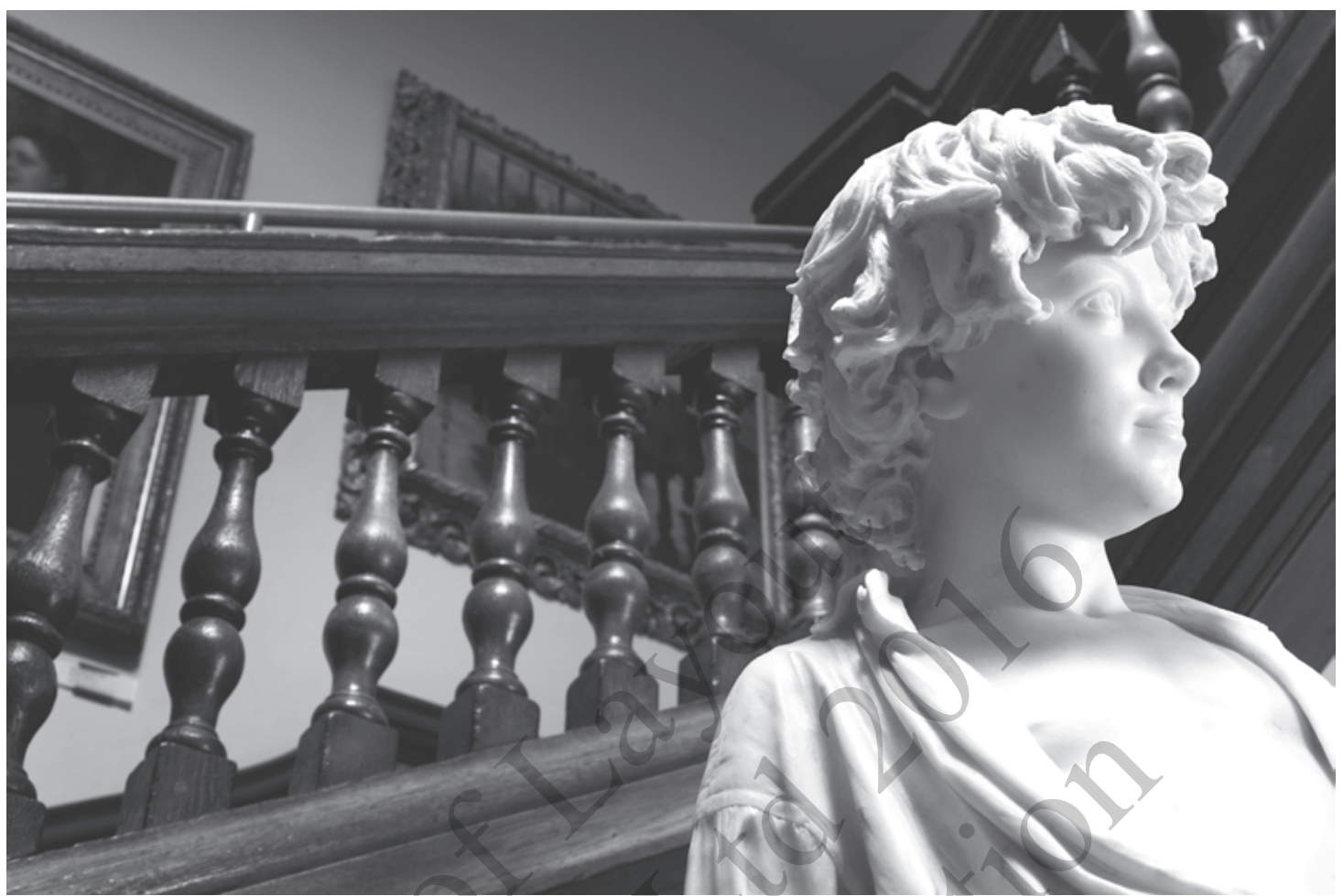

The Foundling Hospital Staircase and Peasant Boy (c.1880), marble, British School. Photo: ( Foundling Museum, London.

The intersection of art, music, philanthropy and education at the Foundling Museum continues to this day, and shapes the museum as a hybrid-object, which exceeds a narrow remit of the museum as information. It has a successful curatorial programme, which creates a form of mediated perception that potentially allows one to see, hear, listen and feel lost-futures reanimated in the present. These lost-futures are felt in atmospheres, intensities and sensations that are highly mediated. The sound of birdsong continually plays as one walks up the stairs and ascends from the sobering anonymity of the ground floor to the ample evidence of the lives of those who gave money to fund the hospital on the second floor. Affectivity is clearly curated in this mediated space and the capacity of the museum to articulate it beyond the museum's walls (on a radio broadcast, for example) is testament to how museums and galleries are no longer approached primarily as producers of meaning, but also as choreographers of experience or part of an experience economy (see Thrift 2000).

However, I also felt that the feeling of being moved (particularly to tears) was not shared. The contagious atmosphere created by the exhibition was diffuse and, although mediated in particular ways, opened to the possibility of other chance meetings in Bracha Ettinger's sense of a matrixial encounter, or what she also terms subjectivity-as-encounter:

A matrixial encounter engenders shared traces, traumas, pictograms, and fantasies in several partners conjointly but differently, accepted 


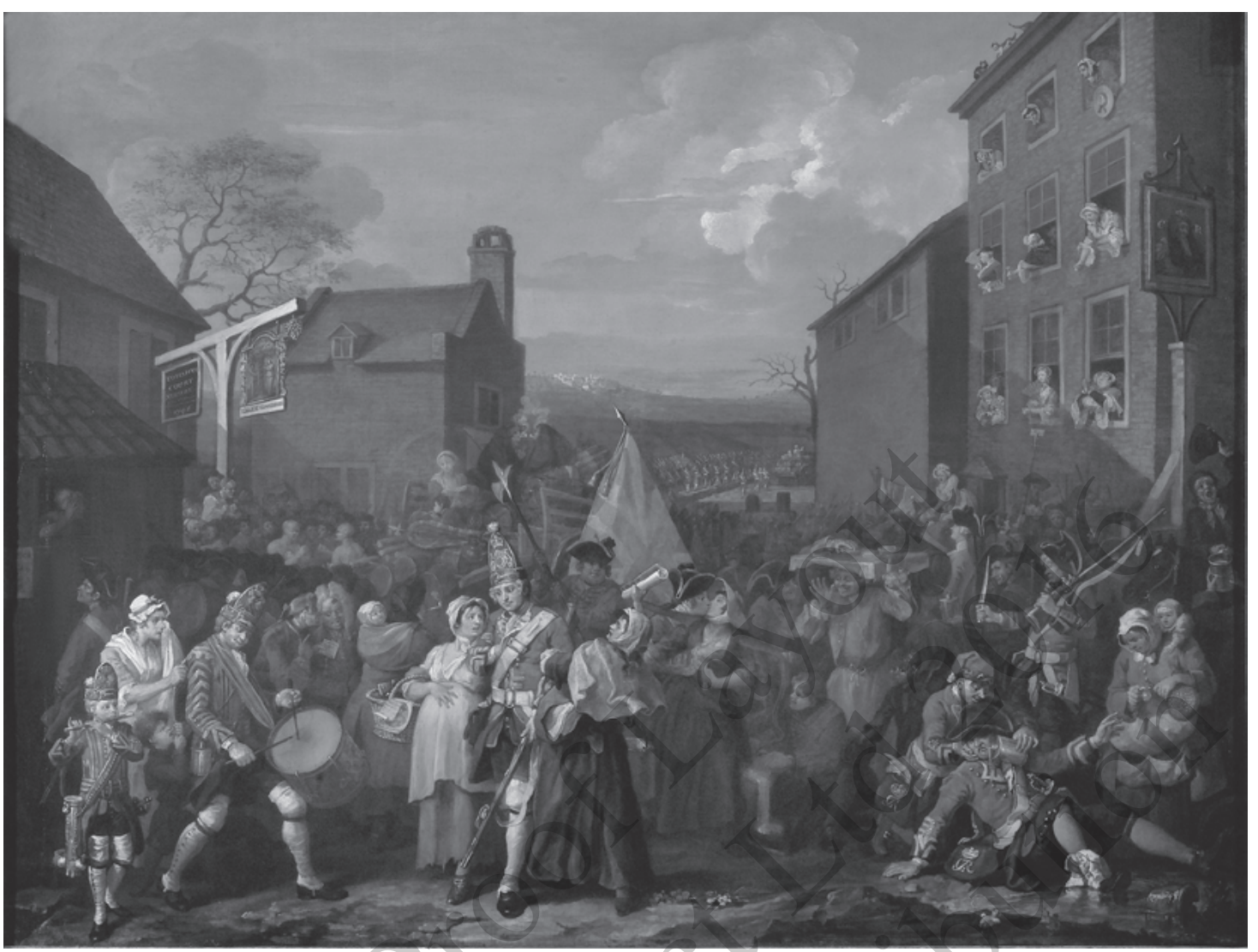

William Hogarth, The March of the Guards to Finchley (1750). Photo: (O) Foundling Museum, London.

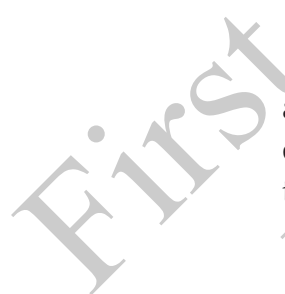

and partly created by diffuse matrixial affects; it engenders nonconscious readjustments of their connectivity and reattunements of transsubjectivity.

(2006: 65)

My own feelings of being moved to tears arose primarily because the design of the museum - encompassing gaps, traces, as well as submerged and displaced narratives, actors and agencies - allowed for my own personal histories to be felt and experienced. This unspoken history of collective trauma, loss, grief, poverty and destitution had been experienced throughout my life as a form of haunting, represented by a house I used to visit as a child to see people who I was told 'were sort of relatives'. The house, I later found out after my grandmother's death, was my great-great-grandfather's house. He was an eminent and respected gentleman who acted as the rate-collector for the provision and distribution of the Poor Law in a small village in the New Forest in Hampshire, United Kingdom. He was a wealthy landowner with two roads named after him, whose own great-granddaughter (my grandmother) had been disinherited due to an illegitimate pregnancy that resulted in my father. The potential damage to his and the family's reputation was managed 
1.

49. by sending her away. This led to her living in destitution and poverty in a small room on a council estate in London with the little boy who was to become my father. This estate later was torn down as part of a slum-clearance programme in the 1960s. I was brought up as a workingclass child who lived and grew up on a council estate and this history (a history of downward mobility) was surrounded by practices of shame and secrecy. These unspoken and embodied histories became entangled with my experience of the suggestive potential of the objects, artefacts and traces of unspoken stories on display at the exhibition. I had found the 'feeling of the foundling' through the affective embodiment of what could and could not be spoken and what became 'available' to me as I attuned to the presences and absences.

The concept of 'availability' is interesting because it allows consideration of the human and non-human actors and agencies that are part of processes of curation when understood affectively and hauntologically. The concept of availability has been developed in work currently being inspired by the writings of Gabriel Tarde (see Candea 2010). Helene Ratner (2009), in particular, argues that suggestion is the basic mechanism of social-psychological life. Engaging with the ontology of subjectivity presumed within Tarde's work, what is seen to define subjectivity is the capacity to affect and be affected. For this reason, Tarde's psychology has been considered an inter- rather than intra-psychology (Blackman 2007). Tarde also argued that 'suggested ideas, beliefs and desires form the basis for often non-conscious but also voluntary) action' (quoted in Ratner 2009: 106). However, Ratner argues it is not that suggestive processes operate merely between human subjects, but that objects can also be suggestive. She also asserts that not all objects are suggestive, for the 'suggestive object facilitates an emotional transformation. Suggestive objects evoke emotions, passions, beliefs and attachments'. As she goes on to argue, 'we do not know in advance which objects are suggestive or which subjects experience their suggestion' (2009: 112-14).

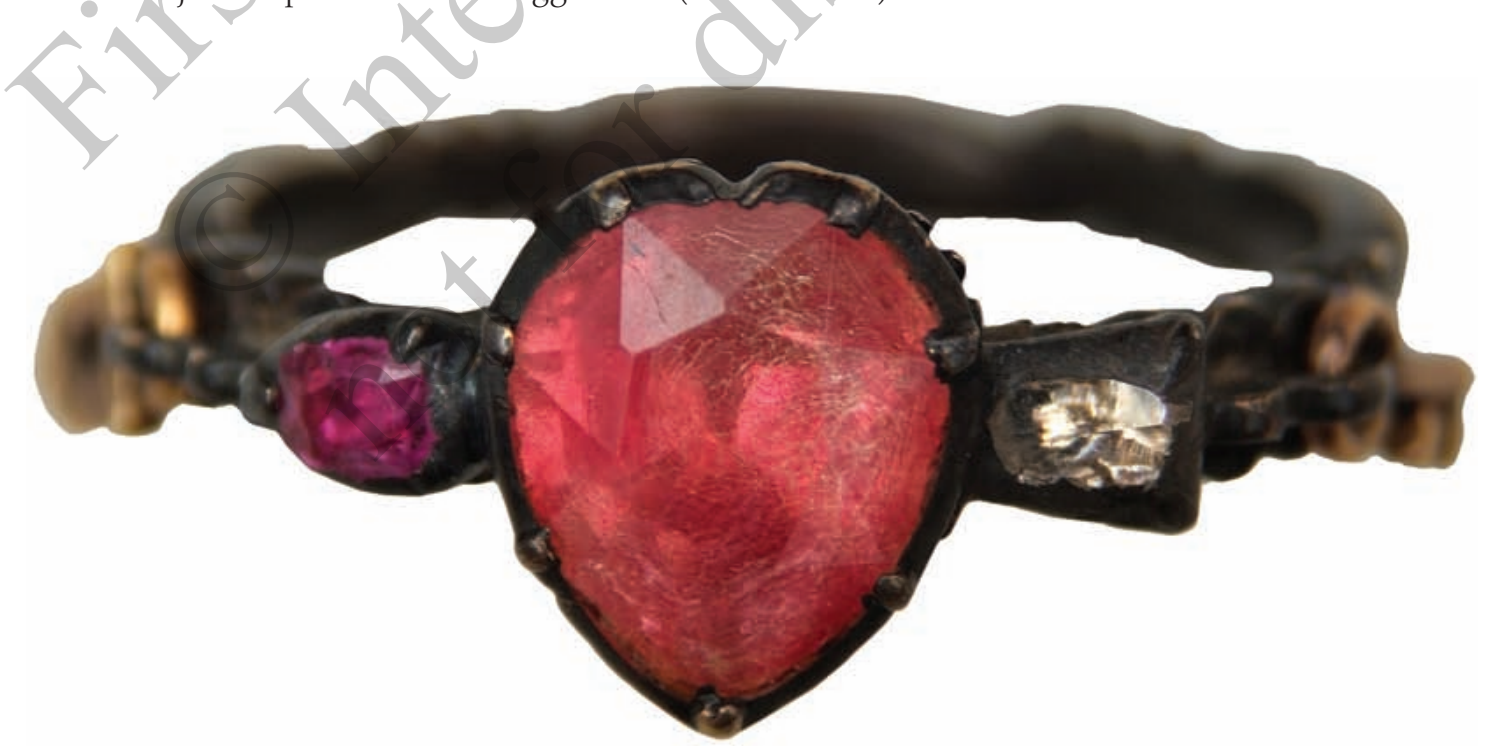

Child's ring token. Photo: () Foundling Museum, London. 
In understanding what becomes suggestive, Ratner also seeks to break down or dissolve the distinction between object and subject and cognition and affect. It is a process, she argues, of understanding and investigating how 'objects become suggestive while subjects learn to become affected by the suggestive objects' (2009: 114). Ratner draws on Vincianne Despret's (2008) notion of 'availability' where availability refers to the way that subjects and objects become reassembled in an emotional articulation. Objects can only be suggestive if there are bodies that are more or less available to objects. Thus, availability importantly has to include some kind of emotional transformation and can take on a conscious and non-conscious form. This argument invites curators to think about what it means for objects to become suggestive in exhibitions, as well as acknowledging that audiences bring personal histories, some of which might allow for an attunement to the suggestive potential of objects.

\section{The Body and Embodiment and Biomediation}

One trend across affect theories is to replace the cognitive, rationalist subject with a subject considered intensive (experiencing through noncognitive registers of experience) and extended through technical forms and practices. So what might it mean to curate affectivity when viewed against this backdrop? There are many theories of the body and embodiment within body studies that might prove of use to curators and curatorial practice (see Blackman 2008). However, I argue that it is important to avoid reducing body to brain. Such reductionism, which is often characteristic of the increasing rapprochement of the arts and humanities towards the sciences, is indicative of a trend among many artists and humanities scholars to turn to the neurosciences to furnish their own accounts of affectivity. This includes what Anna Munster (2011) has termed a 'neurological turn' whereby neurophysiological concepts, objects and entities, such as mirror neurons, the primitive or reptilian brain, or measurements of the apparent speeds or slownesses of the brain's reaction-time(s) provide an imaginary for exploring how affect might be mediated. This imaginary is often subsumed or aligned to the non-cognitive - those experiences, processes and registers of experience that exceed conscious control and attention.

If affect theory is characterized by an increasing rapprochement with the sciences (and particularly the cognitive, neuroscientific and psychological sciences), it does not follow that the brain or brainhood necessarily has to become an object of study. Embodiment does not reduce to the brain, however enfleshed it might become. However, the question of how to invent curatorial practices that work with, through and even against embodied forms of sense-making is a key challenge opened up by these trends across the science and arts. What exactly constitutes the bio in such accounts of biomediation raises important questions that, while not central to curation, are never far from implicitly or explicitly influencing the scene (Clough 2010).

How might affect theory open up to consider phenomena that are already on the margins of the neuro and cognitive sciences? Or those that trouble the boundary between the psychological and the psychic, that are 
continually policed by sceptics, scientists and others? ${ }^{2}$ My transliminal research includes the experiences of voice hearers that I have met as part of my collaborations with the Hearing Voices Network (see Blackman 2001). This network of activists has campaigned for a shift in how voice hearing is understood and responded to within psychiatry and by actual voice hearers. They have cogently and successfully shown that voice hearing is not primarily a sign and symptom of disease, but rather can and should be approached as a meaningful modality of communication. If one is willing to entertain this statement, some rather different questions emerge. One important question I have pursued in my own research is directed to the kinds of technologies of listening and forms of mediated perception that would need to be invented in order to see, hear and listen through another's voice, or another's voices. The question is a technical one. What assemblage of relations (human and non-human) would have to be brought into dialogue and conversation in order for sense-making to emerge?

Given current understandings of exhibitions as communication media, and curators' attempts to orchestrate, amplify and mediate the entanglement of psychic, symbolic, cultural, technical, political and cultural relations carried by objects, artefacts and practices, this question seems particularly important. How can objects be brought to life and remediated in the present such that audiences can be made to move in ways that are not solely about information and cognitive forms of perception? What would a distributed or mediated form of perception look and feel like as part of curatorial practice?

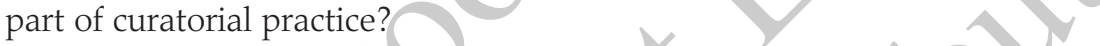

Fish-shaped gambling token. Photo: @ Foundling Museum, London.

These phenomena are the subject of my recent book Immaterial Bodies: Affect, Embodiment, Mediation (2012), that I perform as part of a minor archive of figures, objects, entities and practices, which are brought together under the designation of the subliminal or even transliminal. 
One response to the dethroning of information and cognition as the primary ways in which audiences 'make sense' within museums and exhibitions might be to extend the exhibition outside the space of the gallery, or to use the gallery or museum as the site for multiple intersecting experiences, which are in excess of the direct encounter with curatorial objects, entities and artefacts (what is sometimes identified as a move towards an experience economy). These forms of curating are often conceived in order to create a buzz, include and create different publics, and contribute to atmospheres and intensities, as well as a sense of connection that enlarges what it means to make-sense (see Blackman and Harbord 2010). The experiences that align with such curatorial projects attempt to distribute the exhibition across different sites, agencies, actors and objects. This also might include the remediation of exhibitions within other spaces, such as the cinema, where the exhibition is reworked and repurposed as a cinematic event. What are the implications of a more hauntological approach of entering into suggestive relations with objects, artefacts, devices and experiences? What would it mean to develop a form of distributed or mediated perception that attempts to attune to registers of experience and challenge socialized modes of attention and perception? This might include attempts to attune to submerged narratives and displaced actors and agencies, where a form of subjectivity-as-encounter is enacted in the gallery or exhibition.

\section{Mediated Perception, Affect's Many-Forms and} Subjectivity-as-Encounter

Bracha Ettinger's concept of subjectivity-as-encounter suggests how to move beyond the unidirectional communicative function of the museum where méaning is primarily encoded and audiences relegated as cognitive decipherers of codes. Subjectivity-as-encounter has been developed within the context of media art interventions and experiments across interaction design and digital art to explore what Martin Fritsch and Tony Markussen call 'the manyness of affects forms' (2012: 1). One can learn a lot about affective experience from engaging with how designers and practitioners work with threshold phenomena and affect. The seminal work of Brian Massumi figures prominently in approaches that consider the precognitive implications of affect, specifically with the idea of the event to describe the efficacy of experimentation in this context. The concept of the event relates to the creation of novel links and assemblages that might allow the production of the new, creativity, change and so forth.

One example of such an event comes from the new media artwork of Keith Armstrong, theorized by Lone Bertelsen (2012) who suggests that the artist works with the concept of 'telematic performance and distributed action'. Bertelsen considers what she terms, following Bracha Ettinger (2011: 13), the 'co-affective' power of the new media artwork Intimate Transactions (2005-08). Keith Armstrong, artistic director of the Transmute Collective, the creators of Intimate Transactions, describes the work as collaborative, ecological and concerned with relation. It adopts a 'dual site networked installation' whereby 'two people' interact even though they are in 'two different locations' (quoted in Bertelsen 2012). 
1. Intimate Transactions is an experiment in the form of a telepresence-based

2. installation, which allows two people in geographically separate places to

3. participate simultaneously using only their bodies. They do this by using a

4. physical interface called the Bodyshelf, which is a sound-vibration trans-

5. mission device worn around the neck, which Armstrong likens to a haptic

6. pendant. By gently moving their bodies and interacting via multi-channel

7. sound and digital feedback (in the form of sound and tactile feedback)

8. they gradually form a shared intimacy with each other. Bertelsen equates

9. this to a form of 'collaborative becoming' that potentially produces a

10. movement towards the not-me and the unknown. In this context the

11. artist models subjectivity on the basis of what he terms an ecological

12. approach, which presumes that subjectivities are relational, embedded

13. and embodied, and uses this as the basis to invent a complex material14. semiotic-affective apparatus of experimentation, which brings this into 15. being as a particular kind of experience.

16. Bertelsen associates this process to a 'becoming threshold of 17. borderline' (2012: 46), in which action at a distance enacts a form of 18. distributed co-creative shared subjectivity. Where I depart from Bertelsen 19. and many theories of new media art are the ways in which the potential 20. of an event such as this is then linked to a form of a-signifying semiotics 21. (Lazzarato 2006). The concept of an a-signifying semiotics relates to signs 22. that are seen to tune directly into the body; they trigger a reaction and set 23. something in motion, which very quickly and easily reduces to a materi24. alist, neuro-physiological body. This is a good example of how the chal25. lenges of curating affect might be closed down by aligning such practices 26. to neuro-psychological concepts, which often reduce to the actions of the 27. brain and nervous system, for example. This represents a rather impover28. ished way of theorizing affective processes in the contexts of new media 29. art and threshold phenomena, but importantly it does raise the question 30. of how 'we' participate within processes and practices of mediation and 31. affectivity.

Taking the experimental laboratory as a crucial event for exploring more processual ontologies makes it possible to direct attention to the success or efficacy of different material-semiotic-affective experimental apparatuses. When attuned within curatorial agency it becomes possible to produce more transitive conceptions of subjectivity. Curators can then explore what kind of subject - or model of subjectivity/embodiment - is actively recruited and enacted within different apparatuses, and what this makes possible in terms of particular experiences of both oneself and others, or even oneself as other, or as distributed across a range of others, both human and non-human. I argue that the success or efficacy of the material-semiotic-affective apparatus depends on what qualities, sensitivities and intensities are actively recruited. The concept of the threshold opens up to ambiguity, openness and indeterminacy - a more provisionally liminal space where boundaries dissolve, a modelling of subjectivity that is open to invention and does not presuppose either a neuro-physiological body or distinctly materialist conception of embodiment.

The concept of immateriality that I have developed is derived from threshold phenomena - those that I draw together using the prefix trans - as in transliminal. The prefix 'trans', from Latin, is about moving 


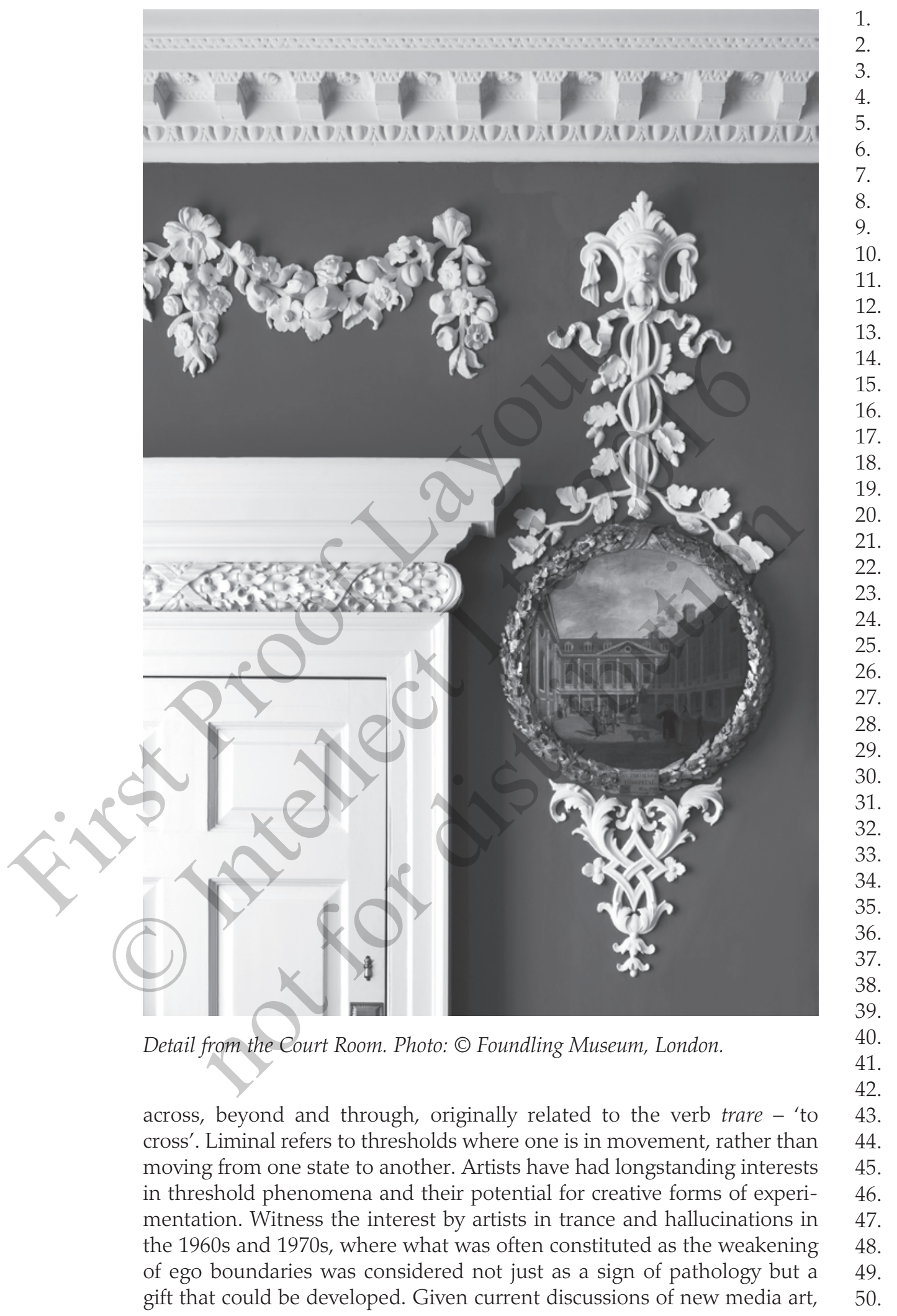


my theorization of mediated perception invites the reconsideration of the kinds of affective experiences that might be possible if curators worked with a transitive approach to subjectivity. ${ }^{3}$ That some new media artists are working with these potentialities illustrates what exceeds and haunts museum and exhibition spaces. Even in exhibitions that primarily appear to position the audience as consumers of meaning and information (within a primarily educational remit, for example), there are and might be hauntological and affective processes at work, as I have tried to illustrate through using my own experience as a case study.

As I have hinted at throughout this article, the question of affect for curators should not be separated from the logics of the market, which increasingly attempt to extract surplus value from those immaterial labours, practices and experiences that exceed and circulate within registers beyond knowing, rational, cognitive subjects. My critical reflections pose curatorial practice as an inventive method - that is, a set of innovative devices for the production of something new or unexpected. Set within the context of galleries and museums approached as hybrid-objects, such an inventive method is always already simultaneously political, economic, symbolic, affective, aesthetic, psychic and historical. What becomes entangled is relevant not only for curators but for different publics and what they bring to museums and gallery spaces in submerged and displaced forms. The question of what becomes 'available', for both conscious and non-conscious reflection and experience, in exhibitions foregrounds the importance of developing new concepts for exploring these relations. As I have suggested here, the concepts of both transliminality and subjectivityas-encounter, as refracted through the insights from affect studies, offer new models for curatorial practice to take forward.

\section{References}

Banham, Rayner (1986), A Concrete Atlantis: US Industrial Building and European Modern Architecture, Cambridge, MA: MTT Press.

Bennett, Tony (1995), The Birth of the Museum: History, Theory, Politics, London and New York: Routledge.

Bertelsen, Lone (2012), 'Affect and Care in Intimate Relationships', Fibreculture Journal, 21, pp. 31-71.

Blackman, Lisa (2001), Hearing Voices: Embodiment and Experience, London and New York. Free Association Books.

Blackman, Lisa (2007), ‘Reinventing Psychological Matters: The Importance of the Suggestive Realm of Tarde's Ontology', Economy and Society, 36: 4, pp. 574-96.

Blackman, Lisa (2008), The Body: The Key Concepts, London and New York: Berg.

Blackman, Lisa (2012), Immaterial Bodies: Affect, Embodiment, Mediation, London and New York: Sage.

Blackman, Lisa (2014), 'Affect and Automaticity: Towards an Analytics of Experimentation', Subjectivity, 7: 4, pp. 362-84.

Blackman, Lisa (2015a), 'The Haunted Life of Data', in Ganaele Langlois, Greg Elmer and Joanne Redden (eds), Compromised Data: From Social Media to Big Data, London and New York: Bloomsbury, pp. 247-71. 
Blackman, Lisa (2015b), 'Social Media and the Politics of Small Data: Academic Value and Post Publication Peer Review', Theory, Culture \& Society, published online before print 17 June 2015, doi: $10.1177 / 0263276415590002$.

Blackman, Lisa and Harbord, Janet (2010), 'Technologies of Mediation and the Affective: Taking the Virtual Environment of Mediacityuk as a Case Study', in Deborah Hauptamann and Warren Neidich (eds), Cognitive Architecture: From Bio-Politics to Noo-Politics: Architecture and Mind in the Age of Communication and Information, Amsterdam: O10, pp. 302-23.

Blackman, Lisa and Walkerdine, Valerie (2001), Mass Hysteria: Critical Psychology and Media Studies, Basingstoke and New York: Palgrave.

Bolter, David and Grusin, Richard (2000), Remediation: Understanding New Media, Cambridge, MA: MIT Press.

Borch, Christian (2012), The Politics of Crowds: An Alternative History of Sociology, Cambridge, UK: Cambridge University Press.

Candea, Mateus (ed.) (2010), The Social after Gabriel Tarde: Debates and Assessments, London and New York: Routledge.

Carsten, Joan (ed.) (2007), Ghosts of Memory: Essays on Remembrance and Relatedness, New York: John Wiley and Sons.

Cho, Grace (2008), Haunting the Korean Diaspora: Shame, Secrecy, Silence and the Forgotten War, Minneapolis: University of Minnesota Press.

Chow, Rey (2012), Entanglements, or Transmedial Thinking about Capture, Durham, NC and London: Duke University Press.

Clough, Patricia T. (2010), 'The Affective Turn: Political/Economy and the Biomediated Body', in Melissa Gregg and Gregory J. Seigworth (eds), The Affect Theory Reader, Durham, NC: Duke University Press, pp. 206-25.

Colomina, Beatriz (1994), Privacy and Publicity: Modern Architecture as Mass Media, Cambridge, MA and London: MIT Press.

Crary, Jonathan (1999), Suspensions of Perception: Attention, Spectacle and Modern Culture, Cambridge, MA: MIT Press.

Despret, Vincianne (2008), 'The Becomings of Subjectivity within Animal Worlds', Subjectivity, 23, pp. 123-39.

Duncan, Carol (2005), Civilizing Rituals: Inside Public Art Museums, London and New York: Routledge.

Ettinger, Bracha (2006), The Matrixial Borderspace: Theory Out of Bounds,

Minneapolis: University of Minnesota Press.

Ettinger, Bracha (2011), 'Uncanny Awe, Uncanny Compassion and Matrixial Transubjectivity beyond Uncanny Anxiety', French Literature Series, 38: 1, pp. 1-30.

Foundling Museum (n.d.), http://foundlingmuseum.org.uk/. Accessed 19 June 2015.

Fritsch, Martin and Markussen, Tony (2012), 'Exploring Affect in Interaction Design, Interaction-Based Art and Digital Art', Fibreculture Journal, 21, pp. 1-160, http://fibreculturejournal.org/wp-content/pdfs/ fc21_FullIssue.pdf. Accessed 30 June 2015.

Gibbs, Anna (2010), 'After Affect: Sympathy, Synchrony, and Mimetic Communication', in Melissa Gregg and Gregory J. Seigworth (eds), The Affect Theory Reader, Durham, NC: Duke University Press. 
1.

2.

3.

4.

5.

6.

7.

8.

9.

10.

11.

12.

13.

14.

15.

16.

17.

18.

19.

20.

21.

22.

23.

24.

25.

26.

27.

28.

29.

30.

31.

32.

33.

34.

35.

36.

37.

38.

39.

40.

41.

42.

43.

44.

45.

46.

47.

48.

49.

50.
Gordon, Avery (2008), Ghostly Matters: Haunting and the Sociological Imagination, Minneapolis: University of Minnesota Press.

Jaynes, Julian (1976), The Origin of Consciousness in the Breakdown of the Bicameral Mind, Boston: Houghton Mifflin.

Kavka, Michka (2008), Reality TV, Affect and Intimacy: Reality Matters, Basingstoke: Palgrave.

Kember, Sarah and Zylinska, Joanna (2012), Life after New Media: Mediation as a Vital Process, London and Cambridge, MA: MIT Press.

Lang, Kurt and Lang, Gladys (1961), Collective Dynamics, New York: Thomas Y. Crowell.

Latour, Bruno (2005), Reassembling the Social: An Introduction to Actor Network Theory, Oxford: Oxford University Press.

Lazzarato, Maurizio (2006), 'Semiotic Pluralism and the New Government Signs', Semiotic Review of Books, 18: 1, pp. 9-12.

Munster, Anna (2011), 'Nerves of Data: The Neurological Turn in/against Networked Media', Computational Culture: A Journal of Software Studies, http://computationalculture.net/article/nerves-of-data DOI/. Accessed 15 June 2015.

Orr, Jackie (2006), Panic Diaries: A Genealogy of Panic Disorder, Durham, NC: Duke University Press.

Ratner, Helene (2009), 'Suggestive Objects at Work: A New Form of Organizational Spirituality?', Distinktion: Scandinavian Journal of Social Theory, 19, pp. 105-21.

Rheinberger, Hans-Jorg (1994), 'Experimental Systems: Historiality, Narration and Deconstruction', Science in Context, 7: 1, pp. 65-81.

Rheinberger, Hans-Jorg (2010), An Epistemology of the Concrete: TwentiethCentury Histories of Life, Durham and London: Duke University Press.

Rose, Nikosa and Abi-Rached, Joelle (2013), Neuro: The New Brain Sciences and the Management of Mind, Princeton and Oxford: Princeton University Press.

Sampson, Tony (2012), Virality: Contagion Theory in the Age of Networks, Minneapolis: University of Minnesota Press.

Thrift, Nigel (2000), 'Still Life in Nearly Present Time: The Object of Nature', Body and Society, 6: 3-4, pp. 34-57.

\section{Suggested Citation}

Blackman, L. (2016), 'Affect, Mediation and Subjectivity-as-Encounter: Finding the Feeling of the Foundling', Journal of Curatorial Studies 5: 1, pp. 32-56, doi: $10.1386 /$ jcs.5,1.32_1

\section{Contributor Details}

Lisa Blackman is Professor in the Department of Media and Communications, Goldsmiths, University of London, UK. She works at the intersection of body studies and media and cultural theory. She is the editor of the journal Body \& Society and co-editor of Subjectivity (with Valerie Walkerdine). Her books include Immaterial Bodies: Affect, Embodiment, Mediation (2012), The Body: The Key Concepts (2008), Hearing Voices: Embodiment and Experience (2001), Mass Hysteria: Critical Psychology and Media Studies (with Valerie Walkerdine, 2001), and the forthcoming 
Haunted Data: Social Media, Affect, Weird Science and Archives of the 1. Future.

Contact: Goldsmiths, University of London, Department of Media and Communications, New Cross, London SE14 6NW, UK.

E-mail: 1.blackman@gold.ac.uk

Lisa Blackman has asserted her right under the Copyright, Designs and Patents Act, 1988, to be identified as the author of this work in the format it was submitted to Intellect Ltd. 